\title{
Enzymatic synthesis of low-trans blends from fractionated mustard oil and palm stearin with linoleic acid by response surface methodology
}

\author{
M. A. Alim, J. -H. Lee ${ }^{1}$, C. C. Akoh ${ }^{2}$, K. - T. Lee ${ }^{1}$ \\ Department of Food Technology and Rural Industries, Bangladesh Agricultural University, Mymensingh-2202, \\ Bangladesh \\ ${ }^{1}$ Department of Food Science and Technology, Chungnam National University, Taejeon, 305-764, South Korea \\ ${ }^{2}$ Department of Food Science and Technology, The University of Georgia, Athens, GA 30602, USA
}

\begin{abstract}
Low-trans blend (LTB) was produced from the fractionated mustard oil (solid phase, S-MO) and palm stearin (PS) through lipase-catalyzed reaction, in which linoleic acid (LA) was intentionally incorporated. For optimizing the reaction condition, response surface methodology (RSM) was employed with three reaction variables such as substrate mole ratio of S-MO to PS $\left(X_{1}\right)$, reaction temperature $\left(X_{2}\right)$ and reaction time $\left(X_{3}\right)$. The predictive models were adequate and reproducible due to no significant lack of fit and the $P$-value of the model was very small $\omega 6 / \omega 3$ ratio, and satisfactory level of coefficient of determination $\left(R^{2}=0.89\right)$ for $\omega 6 / \omega 3$ ratio. The $\omega 6 / \omega 3$ ratio of LTB was affected by substrate mole ratio and reaction temperature but reaction time had no significant effect. For considering the $\omega 6 / \omega 3$ ratio, the optimum condition found $1: 1.7$ substrate mole ratio, 61.42 reaction temperature and $25.85 \mathrm{~h}$ reaction time.
\end{abstract}

Keywords: Low-trans blend, Mustard oil, Palm stearin, Lipase-catalyzed reaction, Response surface methodology, Solid fat content

\section{Introduction}

A trans fatty acid (TFA) is an unsaturated fatty acid whose molecule contains trans configuration at double bonds. Although, TFA is naturally found in some animal-based foods, but the majorities are formed when liquid oils are made into semi-solid fats like shortening and hard margarine through hydrogenation. Before hydrogenation, most naturally occurring unsaturated fatty acids have cis configuration at their double bonds. Partial hydrogenation rearranges the double bonds, converting some of them to the trans configuration and shifting the double bonds along the carbon chains. However, it is reported that high TFA diet causes adverse changes in the plasma lipoprotein profile with increase in low-density lipoproteins (LDL) cholesterol and decrease in high-density lipoproteins (HDL) cholesterol and increase the risk of coronary heart diseases and atherosclerosis $[1,2]$. Furthermore, hydrogenation process has a disadvantage of reducing essential fatty acid. Of late, the need of the development of low and/or zero-trans solid fats is requested in the food industry due to the negative health effect of TFA. Therefore, lipase-catalyzed reaction, as a non-hydrogenated alternative process, is now being explored to develop the low-trans fats [3].

Mustard oil (MO) is commonly used in Bangladesh, and eastern and northern parts of India. MO has a strong smell, hot nutty taste, pungent and sulphury odor, and much used for cooking. This is valuable for human health by reducing the risk of colon tumor incidence and multiplicity as compared to the dietary corn and fish oil [4]. Its major fatty acids are erucic, oleic, linoleic and $\alpha$-linolenic acid $[4,5,6,7]$. $\mathrm{MO}$, possibly owing to the presence of omega-3-fatty acids ( $\alpha$-linolenic), may provide protective effects in the patients with acute myocardial infarction [8]. Actually, oils high in erucic acid are useful for the polymer industry and valuable raw material for manufacture of industrial products such as plasticizers, surfactants, detergents, coatings and polyester, but oil enriched with low erucic acid are recommended for food purposes because oils enriched with high erucic acid may causes an accumulation of triacylglycerol in the heart of rats and other species [9]. High consumption of erucic acid may increase the adrenal cholesterol, cause fibrotic changes in myocardium and increase liver weight and cholesterol $[10,11]$.

Palm oil is widely used in food applications, providing various fractions after winterization process in which palm stearin (PS), one of the fractions, is mainly composed of high melting triacylglycerides [12]. 
For optimizing the lipase-catalyzed reaction, response surface methodology (RSM) has been successfully applied, considering it as an effective and powerful statistical method $[13,14]$.

The purpose of this study was to develop low-trans blend from the fractionated MO and PS through lipase-catalyzed reaction, in which linoleic acid (LA) was intentionally incorporated due to its beneficial health effects. Linoleic acid is an essential fatty acid that human needs to get it from the foods since our body can not synthesize it. For the reaction, factors (substrate mole ratio, reaction temperature and reaction time) were optimized to the $\omega 6 / \omega 3$ ratio (as response) using response surface methodology (RSM) analysis.

\section{Materials and methods}

Mustard oil (MO) was supplied from Agricultural Marketing Co. Ltd (Dhaka, Bangladesh). Lipozyme TL IM was obtained from Novozymes A/C (Bagsvaerd, Denmark). Lipozyme TL IM (175 IUN/g catalytic activity with $0.54 \mathrm{~g} / \mathrm{ml}$ bulk density, $0.3-1.0 \mathrm{~mm}$ particle diameter and $5 \% \mathrm{w} / \mathrm{w}$ water content) is a $1,3-$ specific lipase from Thermomyces lanuginosus which is granulated on the silica. Linoleic acid was obtained from Sigma Chemical Co. (St. Louis, MO, USA). Acetone, n-hexane, choloroform, 2propanol, heptadecanoic acid, and acetic acid were purchased from Fisher Scientific (Norcross, GA, USA). The standard $\alpha$ - tocopherol and pancreatic lipase was obtained from Sigma Chemical Co. All chemicals were of analytical reagent grade.

\section{Winterization}

Mustard oil $(300 \mathrm{~g})$ and acetone $(1500 \mathrm{ml})$ were mixed $(1: 5, \mathrm{w} / \mathrm{v})$ together in 3-L conical flask [15] and placed in a freezer $\left(-16^{\circ} \mathrm{C}\right.$ for $\left.24 \mathrm{~h}\right)$. After winterization, the liquid phase was separated from the solid phase by decanting quickly, and acetone was completely evaporated from solid phase using a rotary vacuum evaporator and a stream of nitrogen with moderate heating $\left(40^{\circ} \mathrm{C}\right)$. The fractionated solid phase of mustard oil (S-MO) was obtained and further used as a substrate for lipase catalyzed reaction.

\section{Experimental design for RSM analysis}

A three-factor and three-level face-centered cube design was chosen to evaluate the combined effect of three independent variables such as substrate mole ratio $\left(X_{1}\right)$, reaction temperature $\left(X_{2}\right)$ and reaction time $\left(X_{3}\right)$. In this study, 17 individual run points were taken for analysis in which 8,6 and 3 replicates were considered as a factorial, axial and center point respectively [16,17].

Using the experimental data, the polynomial equation for the yield of melting point and $\omega 6 / \omega 3$ ratio was shown as below:

$$
Y=\beta_{o}+\sum_{i=1}^{3} \beta_{i} X_{i}+\sum_{i=1}^{3} \beta_{i i} X_{i}^{2}+\sum_{i=1 j=i+1}^{2} \sum_{j=1}^{3} X_{i j} X_{j}
$$

Where, $\beta_{0}, \beta_{i}, \beta_{i i}, \beta_{i j}$ were the regression coefficients for interception, linear, quadratic and interaction terms respectively, and $X_{i}$, and $X_{j}$ were the independent variables. The actual experiments and the independent variables $\left(X_{i}\right)$ with their levels are shown in Table 1. All data were analyzed by the response surface regression (RSREG) procedure of the Statistical Analysis System (SAS) [18] and verified to the polynomial equation after logarithmic transformation [19]. The ridge analysis of RSREG of SAS was used to determine the estimated ridge of maximum or minimum response when the result was a saddle point. Response contour plot and predicted plot were generated using Modde version 5.0 software (Umetrics, Umeå, Sweden).

\section{Lipase-catalyzed reaction}

The S-MO and PS were mixed together as a blend in a screw-capped test tube in proportions of 1:1 (S-MO: PS, w/w), 1:1.5, and 1:2, respectively. Then, $30 \%$ linoleic acid (LA) of the S-MO and PS mixture and lipase (10\% of the total weight of the substrate) was added. Immediately, the mixtures were incubated in an orbital-shaking water bath at $180 \mathrm{rpm}$ following the reaction conditions mentioned in Table 1. 
Table 1. Three-levels and three-factors experimental design arrangements and responses ${ }^{a}$

\begin{tabular}{|c|c|c|c|c|}
\hline \multirow{2}{*}{$\begin{array}{c}\text { Experiment } \\
\text { No. }\end{array}$} & \multicolumn{3}{|c|}{ Factors } & $\begin{array}{c}\text { Response } \\
\left(\mathrm{Y}_{1}, \omega 6 / \omega 3\right)\end{array}$ \\
\cline { 2 - 4 } & $\mathrm{X}_{1}$ & $\mathrm{X}_{2}$ & $\mathrm{X}_{3}$ & 8.3 \\
2 & $1: 1(-1)$ & $55(-1)$ & $12(-1)$ & 10.1 \\
3 & $1: 1(-1)$ & $55(-1)$ & $36(+1)$ & 5.3 \\
4 & $1: 1(-1)$ & $75(+1)$ & $12(-1)$ & 5.3 \\
5 & $1: 1(-1)$ & $75(+1)$ & $36(+1)$ & 12.1 \\
6 & $1: 2(+1)$ & $55(-1)$ & $12(-1)$ & 15.8 \\
7 & $1: 2(+1)$ & $55(-1)$ & $36(+1)$ & 8.9 \\
8 & $1: 2(+1)$ & $75(+1)$ & $12(-1)$ & 8.0 \\
9 & $1: 2(+1)$ & $75(+1)$ & $36(+1)$ & 7.7 \\
10 & $1: 1(-1)$ & $65(0)$ & $24(0)$ & 10.6 \\
11 & $1: 2(+1)$ & $65(0)$ & $24(0)$ & 9.5 \\
12 & $1: 1.5(0)$ & $55(-1)$ & $24(0)$ & 9.3 \\
13 & $1: 1.5(0)$ & $75(+1)$ & $24(0)$ & 7.7 \\
14 & $1: 1.5(0)$ & $65(0)$ & $12(-1)$ & 10.3 \\
15 & $1: 1.5(0)$ & $65(0)$ & $36(+1)$ & 9.2 \\
16 & $1: 1.5(0)$ & $65(0)$ & $24(0)$ & 9.7 \\
17 & $1: 1.5(0)$ & $65(0)$ & $24(0)$ & 9.2 \\
\hline
\end{tabular}

${ }^{\mathrm{a}} \mathrm{X}_{1}=$ substrate mole ratio (S-MO to PS); $\mathrm{X}_{2}=$ reaction temperature $\left({ }^{\circ} \mathrm{C}\right) ; \mathrm{X}_{3}=$ reaction time $(\mathrm{h}) ; \mathrm{Y}_{1}=\omega 6 / \omega 3$ fatty acids ratio

After each reaction, the lipases were removed from the reactant by passing through a $5 \mathrm{ml}$ disposable syringe with PTFE filter $(0.5 \mu \mathrm{m})$. One gram of reactant was weighed and dissolved in $5 \mathrm{ml}$ of hexane. For removing free fatty acids in each reactant, $2 \mathrm{ml}$ ethanol and 3-4 drops of phenolphthalein solution were also added. The mixture was titrated with a $0.5 \mathrm{~N} \mathrm{KOH}$ solution in $20 \%$ ethanol until pink color was appeared. Moderate heating was provided to prevent solidification of reactant during the deacidification. The upper phase was passed through an anhydrous sodium sulfate column and dried with nitrogen putting in the heating module, and then the lipase-catalyzed low-trans blend (LTB) was obtained.

\section{Fatty acid composition}

The produced LTB were separated by thin-layer chromatography (TLC) on a silica gel $60 \mathrm{~F}_{254}$ plate (20 x $20 \mathrm{~cm}$, Merck KGaA, Germany) developed with hexane/diethyl ether/acetic acid (50/50/1, v/v/v). After drying, the bands were displayed by viewing under short wavelengths $(254 \mathrm{~nm})$. The visualized triacylglycerol (TAG) band was scraped off into a test tube and methylated with $3 \mathrm{ml}$ of $6 \% \mathrm{H}_{2} \mathrm{SO}_{4}$ in methanol for $1 \mathrm{~h}$ at $70{ }^{\circ} \mathrm{C}$. Fifty micro liters of heptadecanoic acid (C17:0,1 mg/ml in hexane) as an internal standard was also added in the tube. After putting on ice immediately, $2 \mathrm{ml}$ hexane was added and vortexed for $30 \mathrm{sec}$. The upper layer was passed through an anhydrous sodium sulfate column, and solvent was evaporated with nitrogen. Gas chromatography (GC, Agilent, HP 6890 Series, Avondale, PA), accompanied with auto injector and flame-ionization detector was used for fatty acid analysis. A fused-silica capillary column (SP-WAX, $60 \mathrm{~m} \times 0.25 \mathrm{~mm}$ id, Supelco, Bellefonte, PA) was used for separation. The column temperature was held at $100^{\circ} \mathrm{C}$ for $5 \mathrm{~min}$ and increased to 220 ${ }^{\circ} \mathrm{C}$ at the rate $4{ }^{\circ} \mathrm{C} / \mathrm{min}$, then held for $30 \mathrm{~min}$. The carrier gas was nitrogen, and the total gas flow rate in inlet was $52 \mathrm{ml} / \mathrm{min}$ (constant flow rate) with split mode (50:1). The temperature of injector and detector were 250 and $260{ }^{\circ} \mathrm{C}$, respectively.

\section{Positional fatty acid analysis}

S-MO and LTB (each $7 \mathrm{mg}$ ) were taken in a test tube. Seven milliliters of Tris-HCl buffer (pH 7.6), 1.75 $\mathrm{ml}$ of $0.05 \%$ bile salt in distilled water $(\mathrm{w} / \mathrm{v}), 0.7 \mathrm{ml}$ of $2.2 \% \mathrm{CaCl}_{2}$ in distilled water $(\mathrm{w} / \mathrm{v})$ and $7 \mathrm{mg}$ of pancreatic lipase were mixed for hydrolysis and vortexed for $30 \mathrm{sec}$. Other steps were followed as 
described by Lee and Akoh [20]. The hydrolytic products were separated on TLC plate by developing solvent containing of hexane/ diethyl ether/ acetic acid (50/50/1, v/v/v). The band of monoacylglycerol was scrapped off for methylation and analyzed by GC. The percent of fatty acid at sn-1, 3 position was calculated by the formula: sn-1, $3(\%)=(3 T-s n-2) / 2$ where $T$ is the total fatty acid contents found in S-MO and LTB.

\section{Grinnard reaction}

Fatty acid composition of PS at sn-2 position was determined by Grinnard reaction. A sample (25 to $35 \mathrm{mg}$ ) was dissolved in diethyl ether and $300 \mu \mathrm{l}$ ethyl magnesium bromide mixed together. It was vortexed vigorously for $5 \mathrm{~min}$. After that $3 \mathrm{ml}$ boric- $\mathrm{HCl}$ buffer $(0.27 \mathrm{M} \mathrm{HCl}$ in $0.4 \mathrm{~m}$ boric acid) and 1 $\mathrm{ml}$ diethyl ether were added to the mixture. Again vortexed for $1 \mathrm{~min}$. The upper phase was washed with $3 \mathrm{ml}$ of $0.4 \mathrm{~N}$ boric acid solutions at least two times. The upper phase was passed through sodium sulfate column and diethyl ether was blown up by $\mathrm{N}_{2}$ gas. The sample was separated on TLC plate which was impregnated by $0.4 \%$ boric acid solution and developed in hexane/diethyl ether/ acetic acid (50/50/1, v/v/v). After spraying with $0.2 \%$ 2,7-dichlorofluorescein in methanol, a band corresponding to sn-2 monoacylglycerol was scratched and taken into a test tube for methylation and analyzed by GC as described above.

\section{The tocopherol content analysis}

The high performance liquid chromatography (HPLC) was used for quantitative analysis of atocopherol of PS and S-MO [21]. The HPLC consisted of a Yonglin SP930D dual pump (Yonglin, Anayang, Korea) and Yonglin UV830 detector set a $295 \mathrm{~nm}$. The used column was a Chromsep Cartridge, LiChrosorb Diol ( $5 \mu \mathrm{m}, 3 \times 100 \mathrm{~mm}$, Chromapack, Rartian, NJ, USA) and the mobile phase was a mixture of hexane fortified with $0.1 \%$ acetic acid (1000: $1, \mathrm{v} / \mathrm{v})$. The flow rate was $0.5 \mathrm{ml} / \mathrm{min}$. The area of each peak was integrated by Autochro-2000 software (Yonglin, Anayang, Korea).

\section{Differential scanning calorimetry (DSC)}

The solidifying thermograms of S-MO, PS and LTB were determined with the DSC 2010 differential scanning calorimeter (TA Instruments Inc, New Castle, DE, USA). The base line was obtained with an empty aluminum pan. Purge gas was nitrogen and each analysis required 5 to $9 \mathrm{mg}$ sample. The temperature was increased to 80 and held for $10 \mathrm{~min}$, and then the temperature decreased to -60 ${ }^{0} \mathrm{C}$ at $10{ }^{\circ} \mathrm{C} / \mathrm{min}$. After holding for $10 \mathrm{~min}$, the melting behavior was obtained by heating to $80{ }^{\circ} \mathrm{C}$ at 5 ${ }^{0} \mathrm{C} / \mathrm{min}$. The solid fat content (SFC, \%) was calculated by Universal Analysis 2000 (TA Instruments Inc, New Castle, DE, USA). Each solidifying thermogram was divided at different temperature $(-10,0$, $5,10,15,20,25,30,35$ and $\left.40{ }^{\circ} \mathrm{C}\right)$ and the total crystallization energy $(\mathrm{J} / \mathrm{g})$ was calculated into percentage at each temperature for SFC.

\section{Results and Discussion}

\section{Response surface methodology (RSM)}

The optimum processing factors could be determined by using a minimum number of experiments through the suitable experimental design of RSM. The effects of substrate mole ratio of S-MO to PS $(1: 1,1: 1.5$ and $1: 2)$, reaction temperature $\left(55,65\right.$ and $\left.75^{\circ} \mathrm{C}\right)$ and reaction time $(12,24$ and $36 \mathrm{~h})$ on melting point and $\omega 6 / \omega 3$ ratio of LTB were considered in this study by using RSM. The uncoded variables changed to coded variables (Table 1) with zero mean and standard deviation that had been defined dimensionless [22]. The smaller the $P$-values are the bigger the significance of the corresponding coefficient. In Table 2, analysis of variance (ANOVA) of response surface showed that this experimental model was adequate and reproducible because the $P$-value of the model was very small $(0.0132)$ for $\omega 6 / \omega 3$ ratio and significant lack of fit $(P=0.0389)$ did not exceed the tabulated value 25.00 (5, 2 d.f.). The satisfactory levels of $R^{2}(0.89)$ for $\omega 6 / \omega 3$ ratio were found. The CV (13.32) for $\omega 6 / \omega 3$ ratio also was found. Generally, high value of CV indicates that variation in the mean value is high and does not develop an adequate experimental design satisfactorily [23]. Further, the observed $\omega 6 / \omega 3$ ratio was well correlated with the predicted values showing linear distribution $\left(R^{2}=\right.$ 0.89 for $\omega 6 / \omega 3$ ratio). For response $\omega 6 / \omega 3$ ratio, linear term showed $(P=0.0014)$ significant effect while quadratic $(P=0.9889)$ and cross product $(P=0.3107)$ were not considered as significant terms. 
The least squares technique was used for determining multiple regression coefficients to predict polynomial models for $\omega 6 / \omega 3$ ratio. The values of regression coefficient were $\beta_{0}=4.01338(P=$ $0.8998), \beta_{1}=9.107606(P=0.4273), \beta_{2}=-0.162676(P=0.8741), \beta_{3}=0.530628(P=0.1861), \beta_{11}=-$ $0.222535(P=0.943), \quad \beta_{22}=0.001944(P=0.8033), \beta_{33}=-0.001428(P=0.7922), \beta_{12}=-0.08(P=$ $0.3882), \beta_{13}=0.020833(P=0.782)$ and $\beta_{23}=-0.006667(P=0.1083)$ for $\omega 6 / \omega 3$ ratio, respectively. The following second order polynomial equation explains the experimental data containing values of the coefficients of independent variables $\left(X_{1}\right.$, substrate mole ratio; $X_{2}$, reaction temperature; $X_{3}$, reaction time; and $Y_{1}, \omega 6 / \omega 3$ ratio).

$$
\begin{aligned}
Y_{1}= & 4.01338+9.107606 X_{1}-0.162676 X_{2}+0.530628 X_{3}-0.222535 X_{1}^{2}+0.001944 X_{2}^{2} \\
& -0.001428 X_{3}^{2}-0.08 X_{1} X_{2}+0.020833 X_{1} X_{3}-0.006667 X_{2} X_{3}
\end{aligned}
$$

From Table 2, the results pointed out that the factor $X_{1}$ and $X_{2}$ was significant term for affecting the response $(P<0.05)$, and also no significant effect was observed for factor $X_{3}$ on the response $(P>$ 0.05$,$) for \omega 6 / \omega 3$ ratio. Fig. 1 showed that the $\omega 6 / \omega 3$ ratio of LTB increased linearly with increased substrate mole ratio, and also increased slowly with increase reaction time. On the other hand, the $\omega 6 / \omega 3$ ratio decreased with reaction temperature. Fig. 2 is presented the response contour plots showing the effect of mole ratio (S-MO to PS) and reaction temperature into LTB at different reaction times: 12,24 and $36 \mathrm{~h}$. The $\omega 6 / \omega 3$ ratio of LTB increased linearly with increased substrate mole ratio while the ratio decreased with increase of reaction temperature. Reason may lie in the fact that the incorporation rate of lenoleic acid slowly decreased with increase of reaction temperature.

Table 2. Analysis of variance (ANOVA) of the independent variables for response surface model

\begin{tabular}{|c|c|c|c|c|c|}
\hline $\begin{array}{c}\text { Independent } \\
\text { variables }^{\mathrm{a}}\end{array}$ & d. f. & Sum of squares & Mean squares & F-value & $P$-value \\
\hline $\mathrm{X}_{1}$ & 4 & 36.38 & 9.10 & 6.02 & 0.0202 \\
$\mathrm{X}_{2}$ & 4 & 42.60 & 10.65 & 7.04 & 0.0134 \\
$\mathrm{X}_{3}$ & 4 & 10.54 & 2.64 & 1.74 & 0.2445 \\
\hline
\end{tabular}

${ }^{\mathrm{a}} \mathrm{X}_{1}=$ substrate mole ratio $(\mathrm{S}-\mathrm{MO}$ to $\mathrm{PS}) ; \mathrm{X}_{2}=$ reaction temperature $\left({ }^{\circ} \mathrm{C}\right) ; \mathrm{X}_{3}=$ reaction time $(\mathrm{h})$.

To examine the stationary point and to decide whether it represents a maximum, minimum or saddle point, canonical analysis was performed [24]. The canonical model for the $\omega 6 / \omega 3$ ratio of the LTB describing the character of the response surface were:

$Y_{1}=8.84+0.51 W_{1}^{2}-0.12 W_{2}^{2}-0.46 W_{3}^{2}$

Where, $W_{1}, W_{2}$ and $W_{3}$ are the axes of the response surface. The predicted values of the stationary point were saddle points for both cases because eigenvalues were mixed [23]. Therefore, a ridge analysis was used to determine the estimated maximum or minimum response in which combinations of substrate mole ratio, reaction temperature, and time for LTB with target $\omega 6 / \omega 3$ ratio.

The World Health Organization and Food \& Agriculture Organization recommend a dietary $\omega 6 / \omega 3$ fatty acid ratio ranges from 5 to $10(25,26)$. Therefore, the combination with 1:1.7 substrate mole ratio, $61.42{ }^{\circ} \mathrm{C}$ reaction temperature and $25.85 \mathrm{~h}$ reaction time would be predicted with estimated response $10.76 \pm 0.52$ at coded radius 0.5 from the ridge analysis with maximum responses of $\omega 6 / \omega 3$ ratio.

\section{Fatty acids composition}

Table 3 presents the fatty acid composition of the reaction substrates (S-MO and PS). The S-MO and PS contained 94.3 and $29.8 \%$ total unsaturated fatty acids respectively. Many countries have limited the use of erucic acid in the fat component. The European Union recommends $5 \%$ level in food (27). The major fatty acids in PS were palmitic and oleic acid which composed of 63.6 and $24.5 \%$, respectively. In S-MO, mainly erucic $(45.3 \%)$, a-linolenic $(17.7 \%)$, oleic $(16.3 \%)$ and linoleic acid $(15.0 \%)$, respectively were found. The $\omega 6 / \omega 3$ ratio also important in oil and oil based products. The recommended dietary allowances of $\omega 6 / \omega 3$ fatty acid ratio have been published in several countries 
and organization. A joint committee of the World Health Organization and Food \& Agriculture Organization recommends a $\omega 6 / \omega 3$ dietary ratio between 5 and 10 . In Western diets, the $\omega 6 / \omega 3$ ratio ranged 15 to 16.7 [25]. By comparison, the ratio for corn oil is 45 and for soybean oil 10 . According to nutritional point of view, higher level of unsaturated fatty acids in the sn-2 position is good since it is absorbed easily in the human body [28]. In S-MO, the major fatty acids at $s n-2$ position were linoleic $(39.2 \%)$ and oleic $(36.8 \%)$ acid, respectively. Therefore, higher content of total unsaturated fatty acids $(98.7 \%)$ was found at $s n-2$ position of S-MO, which was further used for transesterification with linoleic acid. PS contained $74.3 \%$ total saturated and $25.7 \%$ total unsaturated fatty acids, respectively at sn-2 position.

\section{a-Tocopherol content}

The a-tocopherol content of PS and S-MO are shown in Table 3. The natural antioxidant such as atocopherol prevents lipid peroxidation by scavenging radicals in membranes and lipoprotein particles [29]. The PS and S-MO contained 0.4 and $3.7 \mathrm{mg} / 100 \mathrm{~g}$ of $\alpha$-tocopherol, respectively.

Table 3. Estimated ridge of maximum response

\begin{tabular}{|c|c|c|c|c|c|}
\hline Coded radius & \multirow{2}{*}{$\begin{array}{c}\text { Estimated } \\
\text { response }\end{array}$} & Standard error & \multicolumn{3}{|c|}{ Uncoded factor values $^{\mathrm{a}}$} \\
\cline { 3 - 5 } & & $\mathrm{X}_{1}$ & $\mathrm{X}_{2}$ & $\mathrm{X}_{3}$ \\
\hline 0.0 & 9.27 & 0.53 & 1.5 & 65.00 & 24.00 \\
0.1 & 9.55 & 0.53 & 1.5 & 64.31 & 24.33 \\
0.2 & 9.84 & 0.52 & 1.6 & 63.60 & 24.68 \\
0.3 & 10.14 & 0.52 & 1.6 & 62.88 & 25.05 \\
0.4 & 10.45 & 0.52 & 1.6 & 62.15 & 25.44 \\
0.5 & 10.76 & 0.52 & 1.7 & 61.42 & 25.85 \\
0.6 & 11.08 & 0.53 & 1.7 & 60.67 & 26.27 \\
0.7 & 11.42 & 0.54 & 1.7 & 59.92 & 26.70 \\
0.8 & 11.76 & 0.56 & 1.7 & 59.17 & 27.15 \\
0.9 & 12.11 & 0.59 & 1.8 & 58.41 & 27.61 \\
1.0 & 12.47 & 0.63 & 1.8 & 57.64 & 28.08 \\
\hline
\end{tabular}

${ }^{\mathrm{a}} \mathrm{X}_{1}=$ substrate mole ratio (S-MO to PS); $\mathrm{X}_{2}=$ reaction temperature $\left({ }^{\circ} \mathrm{C}\right) ; \mathrm{X}_{3}=$ reaction time $(\mathrm{h})$

Table 3. Total and positional distribution of fatty acid contents, and $\alpha$-tocopherol content $(\mathrm{mg} / \mathbf{1 0 0 \mathrm { g }})$ of palm stearin (PS) and solid phase of mustard oil (S-MO)

\begin{tabular}{|c|c|c|c|c|c|c|}
\hline \multirow[t]{2}{*}{ Fatty acids } & \multicolumn{3}{|c|}{ PS } & \multicolumn{3}{|c|}{ S-MO ${ }^{a}(90.5 \%)$} \\
\hline & Total & Sn-2 & $\mathrm{Sn}-1,3$ & Total & Sn-2 & $\mathrm{Sn}-1,3$ \\
\hline 14:0 & $1.4 \pm 0.01$ & $2.0 \pm 0.0$ & $1.1 \pm 0.01$ & $N D^{b}$ & ND & ND \\
\hline $16: 0$ & $63.6 \pm 0.45$ & $66.7 \pm 0.5$ & $62.1 \pm 0.42$ & $4.0 \pm 0.05$ & $0.8 \pm 0.1$ & $5.6 \pm 0.02$ \\
\hline $18: 0$ & $4.9 \pm 0.02$ & $5.6 \pm 0.0$ & $4.5 \pm 0.04$ & $1.7 \pm 0.0$ & $0.5 \pm 0.05$ & $2.3 \pm 0.02$ \\
\hline $18: 1$ & $24.5 \pm 0.3$ & $18.3 \pm 0.4$ & $27.6 \pm 0.25$ & $16.3 \pm 0.05$ & $36.8 \pm 0.02$ & $6.0 \pm 0.19$ \\
\hline $18: 2(\omega 6)$ & $5.1 \pm 0.02$ & $7.4 \pm 0.9$ & $4.0 \pm 0.42$ & $15.0 \pm 0.1$ & $39.2 \pm 0.1$ & $2.9 \pm 0.03$ \\
\hline $18: 3(\omega 3)$ & $0.2 \pm 0.01$ & ND & $0.3 \pm 0.01$ & $17.7 \pm 0.2$ & $21.7 \pm 0.0$ & $15.7 \pm 0.15$ \\
\hline $20: 0$ & $0.3 \pm 0.01$ & ND & $0.4 \pm 0.01$ & ND & ND & ND \\
\hline $22: 1$ & ND & ND & ND & $45.3 \pm 0.3$ & $1.0 \pm 0.0$ & $67.5 \pm 0.4$ \\
\hline$\sum \mathrm{SAF}^{\mathrm{C}}$ & $70.2 \pm 0.49$ & $74.3 \pm 0.5$ & $68.1 \pm 0.48$ & $5.7 \pm 0.05$ & $1.3 \pm 0.15$ & $7.9 \pm 0.04$ \\
\hline$\sum \mathrm{UFA}^{\mathrm{d}}$ & $29.8 \pm 0.33$ & $25.7 \pm 1.3$ & $31.9 \pm 0.68$ & $94.3 \pm 0.65$ & $98.7 \pm 0.12$ & $92.1 \pm 0.77$ \\
\hline \multirow[t]{2}{*}{$\omega 6 / \omega 3$ ratio } & 25.5 & & & 0.85 & & \\
\hline & & PS & & & S-MO & \\
\hline$\alpha$-tocopherol & & $0.4 \pm 0.06$ & & & $3.7 \pm 0.1$ & \\
\hline
\end{tabular}

a S-MO; fractionated mustard oil (solid phase) after winterization at $-16{ }^{\circ} \mathrm{C}$ for $24 \mathrm{~h}$. Mustard oil (300 g) and acetone (1500 ml). ${ }^{\mathrm{b}}$ ND means not detected. ${ }^{c}$ Total sum of saturated fatty acid. ${ }^{d}$ Total sum of unsaturated fatty acid. 

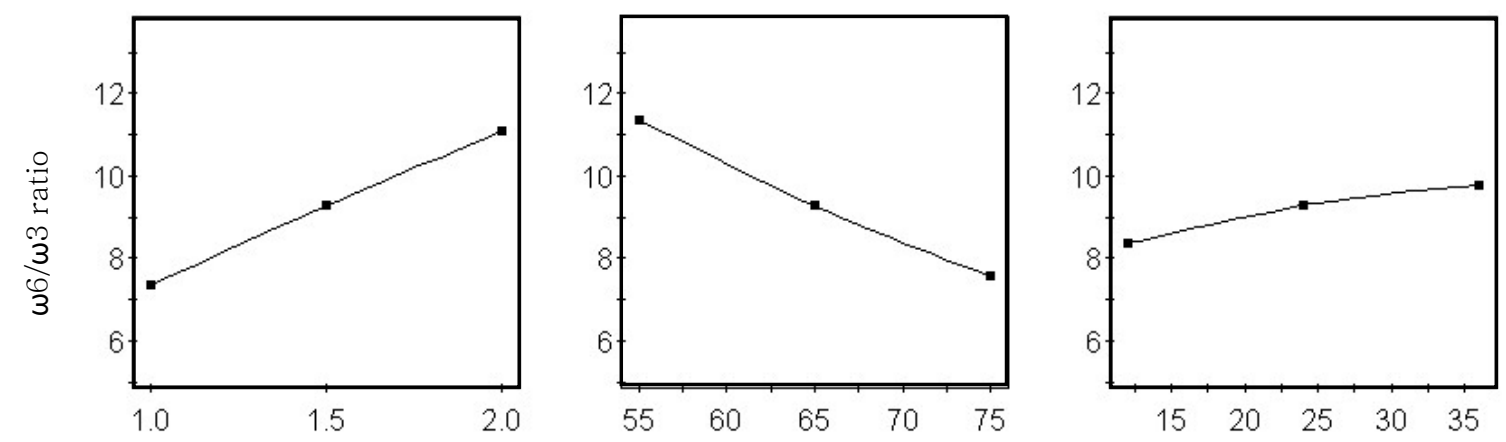

Fig. 1. Prediction plot for $\omega 6 / \omega 3$ fatty acids ratio of lipase-catalyzed low-trans blend (LTB) by effects of mole ratio of S-MO and PS (A), reaction temperature $(B)$ and reaction time $(C)$.

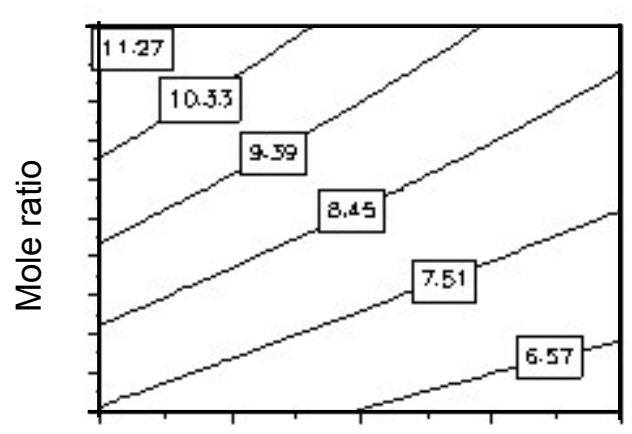

Temperature $\left({ }^{\circ} \mathrm{C}\right)$

Time $(\mathrm{h})=12$

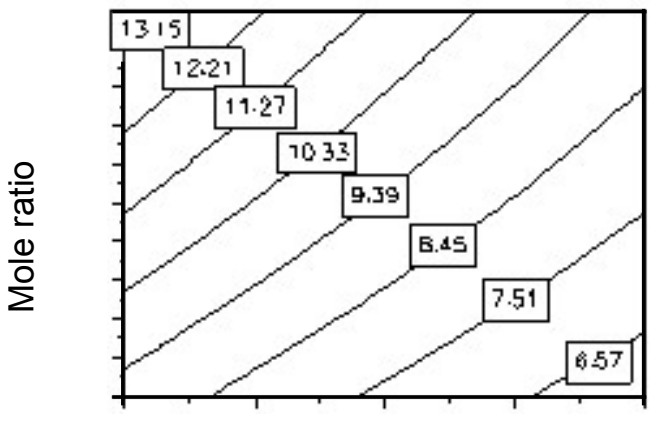

Temperature $\left({ }^{\circ} \mathrm{C}\right)$

Time $(\mathrm{h})=24$

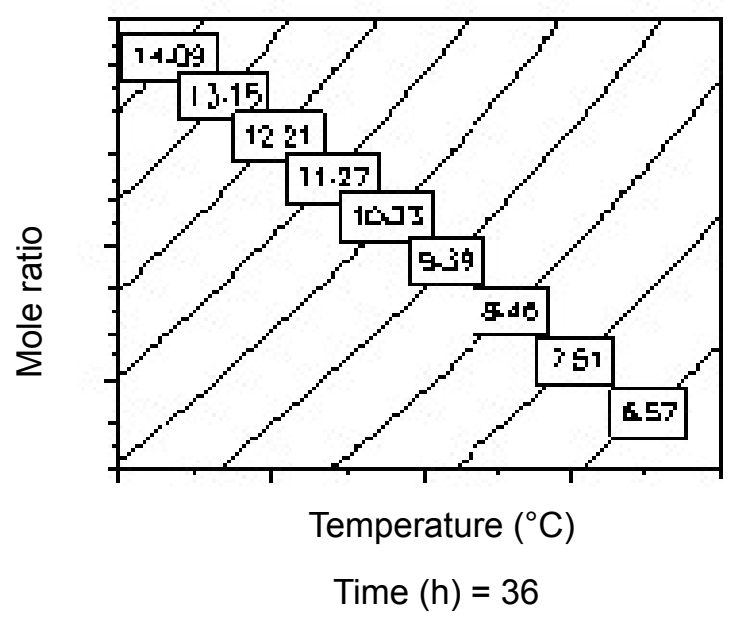

Fig. 2. Response contour plots for $\omega 6 / \omega 3$ fatty acids ratio showing the effect of mole ratio (S-MO to PS) and reaction temperature into low-trans blend (LTB) at different reaction times: $12 \mathrm{~h}(\mathrm{~A}), 24 \mathrm{~h}(\mathrm{~B})$ and $36 \mathrm{~h}(\mathrm{C})$.

\section{Solid fat contents (SFC)}

The SFC of PS and S-MO are given in Table 4. Melting properties such as the melting point and SFC are considered as important factors for the texture of solid fats. The SFC of solid fat (e.g., margarine and butter) is responsible for physical characteristics [30]. For S-MO, SFC at $-10{ }^{\circ} \mathrm{C}$ was $72.1 \%$ while most phases were liquid at $10{ }^{\circ} \mathrm{C}(0.8 \%$ SFC $)$. The SFC of PS at -10 was $99.6 \%$, indicating that most phases were solid. When temperature increased to room temperature ranges from 20 to $25{ }^{\circ} \mathrm{C}$, SFC ranged from 71.7 to $73.6 \%$. Even at $40{ }^{\circ} \mathrm{C}$, SFC of PS was $43.3 \%$. 
Table 4. Solid fat content (\%) of fractionated mustard oil (S-MO) and palm stearin (PS)

\begin{tabular}{|c|c|c|c|c|c|c|c|c|c|c|}
\hline \multirow[t]{2}{*}{ Lipids } & \multicolumn{10}{|c|}{ Temperature $\left({ }^{\circ} \mathrm{C}\right)$} \\
\hline & -10 & 0 & 5 & 10 & 15 & 20 & 25 & 30 & 35 & 40 \\
\hline $\mathrm{S}-\mathrm{MO}^{\mathrm{a}}$ & 72.1 & 43.9 & 18.8 & 0.8 & - & - & - & - & - & - \\
\hline PS & 99.6 & 92.8 & 86.3 & 78.4 & 74.0 & 73.6 & 71.7 & 63.0 & 53.2 & 43.3 \\
\hline
\end{tabular}

${ }^{a}$ S-MO; fractionated mustard oil (solid phase) after winterization at $-16{ }^{\circ} \mathrm{C}$ for $24 \mathrm{~h}$. Mustard oil (300 ml) and acetone (1500 ml) were mixed $(1: 5, v / v)$

\section{References}

Aaes-Jorgensen, E. Nutritional value of rapeseed oil, in Rapeseed Cultivation, Composition, Processing and Utilization, ed by Appelqvist L-A and Ohlson R. Amsterdam, Elsevier Publishing Company; 1972. p. 301-353.

AOCS. 1990. Official methods and recommended practices of the American Oil Chemists' Society. $4^{\text {th }}$ edn. Champaign, II: AOCS press.

Beare-Rogers, I.L, Nero, E.A., Heggtvert, H.A., Can. Inst. Food Technol. J. 1971;4:120-124.

Beare-Rogers JL, Nera EA, Craig BM. Cardiac lipids of rats and gerbils fed oils containing $C_{22}$ fatty acids. Lipids 1972;7:548-552.

Daniel WW. Biostatistics: A foundation for analysis in the health sciences $\left(5^{\text {th }}\right.$ ed. $)$. New York: Wiley:1991.

Dwivedi C, Muller LA, Goetz-Parten DE, Kasperson K, Mistry VV. Chemopreventive effects of dietary mustard oil on colon tumor development. Cancer Lett 2003; 196:29-34.

Edible oils and fats: level of erucic acid. Council Directive 76/621/EEC, 1976; Commission Directive 96/4/EC, 1996, Brussels, Nelgium.

Esterbauer H, Dieber-Rotheneder M, Striegl G., Waeg G. Role of vitamin E in preventing the oxidation of low-density lipoprotein. Am J Clini Nutri 1991;53:314-321.

Fernandez-Escober J, Dominguez J, Marti A Fernandez-Martinez JM. Genetics of erucic acid content in interspecific hybrids of Ethiopian mustard (B. carinata A. Braun) and rapeseed (B. napus L.). Plant Breeding arciovasc 1988;100:310-315.

Hamam F, Shahidi F. Lipase-catalyzed acidolysis of algal oils with capric acid: Optimization of reaction conditions using response surface methodology. J Food Lipids 2004;11:147-163.

Huang K, Akoh CC. Optimization and scale-up of enzymatic synthesis of structured lipids using RSM. J Food Sci 1996;61:137-141.

Laia, OM, Ghazalia HM, Cho F, Chong CL. Physical and textural properties of an experimental table margarine prepared from lipase-catalysed transesterified palm stearin: palm kernel olein mixture during storage. Food Chem 2000;71:173-179.

Lee KT, Akoh CC. Immobilized lipase-catalyzed production of structured lipids with eicosapentaenoic acid at specific positions. JAOCS 1996;73(5):611-615.

Ming LO, Ghazali HM, Let CC. Use of enzymatic transesterified palm stearin-sunflower oil blends in the preparation of table margarine formulation. Food Chem 1999;64:83-88.

Montgomery DC. Response surface methods and designs: In Design and analysis of experiments. New York: John Wiley and Sons:1991.

Myers RH, Montgomery DC. Response surface methodology: Process and product optimization using designed experiments. $2^{\text {nd }}$ ed., New York: John Wiley and Sons:2002.

Parcerisa J, Codony R, Boatella J, Rafecas M. Fatty acids including trans content of commercial bakery products manufactured in Spain. J Agric Food Chem 1999;47:2040-2043.

Pretch D, Molkentin J. Recent trends in the fatty acid composition of German sunflower margarines, shortening and cooking fats with emphasis on individual C16:1, C18:1, C18:2, C18:3 and C20:1 trans isomers. Nahrung 2000;44:222-228.

Pritchard JLR. Analysis and properties of oilseeds. In: Rossell JB, Pritchard JLR, eds. Analysis of oilseeds fats and fatty foods. London: Elsevier; 1991. p. 80-95.

Quinlan P, Moore S. Modification of triacylglycerols by lipases: Process technology and its application to the production of nutritionally improved fats. INFORM 1993;4:580-585.

Roche HM. Unsaturated fatty acids. Proc Nutri Soc 1999;58(2):397-401.

SAS Statistics Software, release 8.2; SAS Institute; Cary; NC:2000.

Shieh CJ, Akoh CC, Koehler PE. Four factor response surface optimization of the enzymatic modification of triolein to structured lipids using capric acid. JAOCS 1995;72:619-623.

Simopoulos AP. The importance of the ratio of omega-6/omega-3 essential fatty acids. Biomed Pharmacother 2002;56(8):365-379.

Singh RB, Niaz MA, Sharma JP, Kumar R, Rastogi V, Moshiri M. Randomized double blind placebo controlled trial of fish oil and mustard oil in patients with suspected acute myocardial infarction: the Indian experiment of infarct survival 4, Carciovasc Drug Ther 1997;11:485-491.

Thompson D. Response surface experimentation. J Food Proce and presser 1982;6:155-188.

Wanasundara UN, Shahidi F. Concentration of omega-3 polyunsaturated fatty acids of seal blubber oil by urea complexation: Optimization of reaction conditions. Food Chem 1999;65:41-49.

Webster G. Small scale processing of vegetable oil for niche markets. Lipid Technol News 1998;4:38-43.

Yu F, Kim SH, Kim NS, Lee JH, Bae DH, Lee KT. Composition of solvent-fractionated rice bran oil. J Food Lipids 2006;13:286-297.

Zaliha O, Chong CL, Cheow CS, Norizzah AR, Kellens MJ. (2004). Crystallization properties of palm oil by dry fractionation. Food Chem 2004;86:245-250. 